\title{
Capacidad de búsqueda bibliográfica: investigación formativa con estudiantes de Bacteriología y Laboratorio Clínico de la Universidad Colegio Mayor de Cundinamarca
}

\author{
Jeannette Vargas Hernández', Helena Gacharná de Beltrán² \\ 1. Magíster, Candidata a Doctorado en Educación Matemática. Universidad Colegio Mayor de Cundinamarca. \\ 2. Química. Universidad Colegio Mayor de Cundinamarca. \\ Correspondencia: hgacharna@gmail.com \\ Recibido 18-02-08 / Aceptado 16-03-08
}

\section{Resumen}

La investigación formativa como espacio que busca educar para la investigación, se aborda desde dos experiencias que toman, como eje central, la búsqueda bibliográfica, y se conectan en una dependencia no sólo temporal sino también de actitudes y habilidades que se planean y desarrollan en el primer semestre, a través del trabajo independiente en matemáticas mediante la invitación a bibliotecas e indagación sobre sus servicios. Luego se pasa a revisión de bases de datos, revistas y temas específicos, estos últimos por medio de palabras clave: ecuación, número e, logaritmo, variación, covariación, función lineal, función cuadrática, función exponencial, función logarítmica.

La búsqueda bibliográfica se retoma en el segundo semestre, en el espacio denominado Orientación y Seguimiento, allí el enfoque se organiza dirigido a la elaboración de un artículo de revisión, pasando también por fases de informes verbales sobre definición y generalidades de la temática elegida. Luego se particulariza el aspecto a tratarr dentro la temática elegida, siendo importante la citación de bibliografía y finalmente la presentación del artículo de revisión. Este escrito tiene como objetivo compartir la experiencia que se llevó a cabo en dos asignaturas para fortalecer la cultura investigativa en la Universidad Colegio Mayor de Cundinamarca.

Palabras clave: base de datos, cultura investigativa, investigación formativa, matemáticas, química, tutoría.

\section{Abstract \\ Ability to research bibliography: a formative investigation with students of Bacteriology and Clinical Laboratory}

Formative research as a space that seeks to educate for research, is approached from two experiences which take, as a central axis, the bibliographical research, and a dependency not only temporary but also of attitudes and abilities that are planned and developed in the first semester, through independent work in mathematics by means of the invitation to libraries and investigation of their services. Soon one goes to revision of magazines, data bases and specific subjects, by means of key words: equation, number e, logarithm, variation, co variation, linear function, quadratic function, exponential function, logarithmic function.

Bibliographical research is retaken in the second semester, in the space called Direction and Pursuit. The approach is organized there and directed to the elaboration of a revision article, also going through phases of verbal 
information over definition and generalities of the chosen topic. Afterwards, the aspect is specified in the selected subject matter, being important the quotation of the bibliography and, finally, the presentation of the review article. This paper's objective is to share the experience that was carried out in two subjects to enhance the investigative culture in the University Colegio Mayor de Cundinamarca.

Key words: chemistry, data base, formative investigation, investigative culture, mathematics, tutorial.

\section{Introducción}

El actual interés en las instituciones de educación superior por la investigación formativa, se refleja no sólo en disposiciones legales sino también en los proyectos educativos y en las diversas estrategias que, tanto docentes como directivos, han tratado de organizar con miras a abordar este espacio.

Frente a este compromiso, es imperioso gestar y compartir con la comunidad académica estrategias tendientes a formar y fortalecer la cultura investigativa. Es en este sentido, que en el Programa de Ciencias Básicas de la Universidad Colegio Mayor de Cundinamarca, Bogotá, Colombia, se emprendieron dos experiencias con el fin de aportar a la cultura investigativa, a través de un espacio en el cual se cultiva la capacidad de búsqueda bibliográfica, como una herramienta indispensable para la formación en investigación.

Se asume que la cultura investigativa comprende, como toda manifestación cultural, organizaciones, actitudes, valores, objetos, métodos y técnicas, relacionadas con el fomento, desarrollo y difusión de la investigación incluyendo la pedagogía de la misma. A partir de la segunda mitad de la década del 90, en las instituciones de educación superior de nuestro país, se consolida cuando se comenzó a hablar de investigación formativa entre estudiantes y docentes en el proceso de desarrollo del currículo de un programa, y que es propio de la dinámica de la relación con el conocimiento que debe existir en todos los procesos académicos, tanto en el aprendizaje, por parte de los alumnos, como en la renovación de la práctica pedagógica por parte de los docentes (1).

La investigación formativa tiene varias acepciones, dentro de las cuales, de acuerdo a nuestra experiencia se organizaron e identificaron teniendo en cuenta el concepto del Consejo Nacional de Acreditación (2). Se asume la investigación formativa como el espacio que busca formar en y para la investigación, a través de actividades que no hacen parte necesariamente de un proyecto concreto de investigación. Su intención es familiarizar al estudiante con este proceso, su naturaleza, sus fases y funcionamiento.

En relación con las fases de una investigación científica, una de las primeras etapas consiste en la búsqueda bibliográfica, actividad que pretende la recopilación y evaluación de documentos (3). Esta etapa es vista por muchos autores como una exploración de aquello que se ha escrito sobre un determinado tema o problema, o como una recopilación sistemática de la información publicada relacionada sobre el mismo. Para su ejecución, algunos de ellos la dividen en dos partes: la búsqueda y la revisión de la bibliografía (4).

Esta búsqueda bibliográfica puede conducir a la elaboración de un artículo de revisión, que no es una publicación original y su finalidad es examinar la bibliografía publicada y situarla en cierta perspectiva (5). Igualmente, atendiendo a COLCIENCIAS (6), un artículo de revisión, es el resultado de una investigación donde se analizan, sistematizan e integran las investigaciones publicadas o no publicadas, sobre un campo en ciencia o tecnología, con el fin de dar cuenta de los avances y las tendencias de desarrollo. Dicho documento presenta una cuidadosa revisión bibliográfica de por lo menos 50 referencias.

\section{Metodología}

Este es un trabajo de corte descriptivo y aplicado, de tipo cualitativo, donde se consideraron las siguientes etapas:

1. Presentación de la problemática. 
2. Elaboración de un marco teórico que involucra:

- Investigación.

- Investigación formativa.

- Búsqueda bibliográfica.

- Artículos de revisión.

3. Determinación del período de tiempo durante el cual se llevaría a cabo la experiencia práctica.

4. Análisis de las experiencias prácticas de los profesores de Ciencias Básicas y selección de elementos a retomar.

5. Proceso de seguimiento sobre el impacto del trabajo en semestres posteriores.

6. Presentación de resultados y sugerencias.

Población: los estudiantes participantes en estas experiencias se encuentran en primer y segundo semestres de pregrado, en Bacteriología y Laboratorio Clínico en la Universidad Colegio Mayor de Cundinamarca. Se abordó esta experiencia desde los componentes temáticos de química y matemáticas, para aportar a la cultura investigativa de los estudiantes, a través de un espacio cuyo objetivo es desarrollar la capacidad de búsqueda bibliográfica como una herramienta indispensable para su formación en investigación.

\section{Matemáticas aplicadas}

Al focalizar el interés en el desarrollo de la capacidad de búsqueda bibliográfica de los estudiantes, como una herramienta indispensable para su formación en investigación, desde las horas presenciales de matemáticas aplicadas se planteó una propuesta para los alumnos de primer semestre, vinculada a su trabajo de tiempo independiente. La experiencia en Matemáticas Aplicadas se inicia en el segundo semestre de 2003, con la lectura del libro El Diablo de los Números (7), libro que además de poseer ilustraciones atractivas y un enfoque por "noches", examina con rigor y sin rigidez, algunos de los temas abordados en el semestre (8), siendo esta propuesta de lectura, una experiencia que nace de inquietudes sobre los bajos niveles de interpretación de lectura y dificultades en la comprensión de conceptos, que se observaron en los estudiantes que participaron de 1999 a 2002 (9), en el desarrollo de ejercicios sobre la lectura titulada Medición, de la colección Sigma (10).

Estas experiencias se evaluaron y fueron evolucionando para transformarse en los semestres posteriores, de un único libro o artículo, en una consulta a bibliotecas. Cambios que permitieron mayor correlación con las exigencias de investigación formativa planteadas en el segundo semestre desde asignatura orientación y seguimiento, espacio vinculado con química II. La actual propuesta en el espacio de investigación formativa de matemáticas aplicadas es presentada por pasos, al iniciar el semestre. En cada fecha se va indicando el proceso a seguir, los logros y el informe que se espera de dicho proceso.

\section{Desarrollo}

Paso 1. La propuesta de acercamiento a la búsqueda bibliográfica inicia con la invitación a los estudiantes de primer semestre, para que conformen grupos de cinco o seis integrantes y elijan una biblioteca de una universidad pública o privada, o una biblioteca de la Red de Bogotá. Luego de elegida la biblioteca, los estudiantes deben proceder a informarse sobre los requisitos para poder ingresar físicamente, no virtualmente. El día de la visita, centran su atención en los servicios que presta la biblioteca y recogen información en torno de las revistas de educación matemática y los volúmenes que allí se encuentren. El primer reporte escrito debe contener información sobre los servicios que son ofrecidos en la Biblioteca y las formas de acceder a ellos, e incluir una tabla en donde presenten nombre de las revistas y datos generales concernientes a ellas. La puesta en común de esta experiencia, se lleva a término en el horario de tutoría grupal.

Paso 2. Aproximadamente un mes después de la puesta en común, se propone una segunda visita que los estudiantes realizarán a la biblioteca de la Universidad Colegio Mayor de Cundinamarca. Para esta oportunidad, aprovechando que la Universidad cuenta con un "curso de iniciación" organizado por la Biblioteca, los estudiantes llevan tres preguntas sobre la manera de acceder a bases de datos, la forma de consultar libros en la biblioteca o pedir préstamos ínter bibliotecarios, y la consulta de un documento específico. El informe final debe contener las respuestas a este cuestionario. Este segundo informe escrito es revisado por el profesor, quien formula 
las observaciones por grupos y recomendaciones generales, tanto para los informes como para los puntos específicos tratados.

Paso 3. Según los resultados de estas dos etapas, se orienta el trabajo de consulta hacia artículos en una única revista y varios volúmenes, o varias revistas, o artículos que se puedan localizar en Internet. La información a consultar varía cada semestre, atendiendo a las necesidades de los grupos. Dentro de los temas que se han propuesto para que los estudiantes consulten se encuentran: ecuación (11) variables (12), variación (13,14), covariación (15) función lineal $(16,17)$, función cuadrática y número e $(18,19)$ logaritmos $(20)$, función exponencial $(21)$ y función logarítmica (22).

En esta etapa del trabajo, las palabras clave son las que adquieren importancia. La revisión que deben realizar por grupos, consiste ahora en buscar con las mismas, los artículos que traten la temática asignada y llevar una copia de éstos a clase, para allí con ayuda del profesor, decidir cuál ofrece una información comprensible para los estudiantes.

Paso 4. El último informe consiste en una síntesis del artículo seleccionado, dando a conocer los aspectos que tienen relación con los conceptos trabajados en clase y preguntas sobre elementos que los integrantes del grupo no lograron entender.

Monitoría. Además de la coordinación del profesor, se nombra un monitor que tiene a su cargo 3 o 4 grupos. Tiene como función principal el control de entregas. Después de recibidos los tres primeros informes, su función se torna más exigente puesto que debe estar pendiente de los grupos en su entrega vía e-mail, realización de las correcciones sugeridas, y que la información consultada sobre palabras clave corresponda a la realidad y realizar un control de la entrega final.

\section{Ejemplo del paso 2.}

A continuación se presenta el informe de un grupo integrado por seis estudiantes de primer semestre del programa de bacteriología y laboratorio clínico, que cursaban matemáticas aplicadas en el segundo semestre de 2007.

\section{Base de datos y consultas}

- Consultas dentro de la misma biblioteca de la universidad.

- Consultas sobre libros específicos.

- Préstamo ínter bibliotecario.

\section{Acceso a la base de datos de la Universidad Colegio Mayor de Cundinamarca}

Para tener acceso a todas las bases de datos de la universidad exceptuando en jurídica colombiana, primero debe ser miembro de la cuenta entrar a la pagina Web de la universidad, si vamos a acceder desde nuestra biblioteca escogemos "acceso local" si no "acceso remoto", y entrar a los iconos de las bases, luego escribir el código del estudiante y dígitos de identificación que se registró en la universidad. Escogemos la opción biblioteca, aparecen varios iconos tomamos la opción bases datos, y en esta ocasión podemos escoger de las bases de datos disponibles en la Universidad.

PROQUEST: provee una colección de más de 30 bases de datos en texto completo en todas las áreas del conocimiento incluye mas de 8.000 revistas y mas de 2.000 tesis doctorales.

DOYMA: base de datos medico científica con 47 títulos en espańol en texto completo.

EBRARY: colección de libros electrónicos en línea en las áreas de humanidades, puede consultar más de 10.000 obras en texto completo.

JURIDICA COLOMBIANA: contiene la legislación colombiana. Puede consultar más de 387.000 documentos en texto completo.

\section{Requisitos para acceder a libros de diferentes bibliotecas}

1. Conocer los procedimientos de las bibliotecas.

2. Suministrar datos personales requeridos y el carnet institucional para elaborar el registro en la base de datos del sistema de biblioteca.

- Formulario en la biblioteca y se completa con los siguientes datos.

- Biblioteca a consultar.

- Número topográfico.

- Autor y titulo. 
- Edición y año de publicación.

3. Presentar el carné de biblioteca vigente, a la entrada de la biblioteca, para el ingreso al banco de usuarios y el acceso a los servicios bibliotecarios.

4. Retirar el material personalmente, pues el préstamo es intransferible.

5. Devolver el material prestado en la fecha indicada en el comprobante, en las tarjetas de lector y vencimiento.

\section{Acceso a documentos de la biblioteca}

Después de acceder a la base de datos se necesita encontrar el índice de búsqueda en el cual parecen las opciones para encontrar la información necesitada de acuerdo al tema, libro o documento deseado y también búsqueda por palabra.

\section{Ejemplo del paso 4.}

El estudiante titula este informe: Relación del artículo Razonamiento Covariacional de Carlson, M y colaboradores (15), con los Temas aprendidos durante el Semestre. El estudiante toma una parte del artículo y la cita entre comillas, así: "Eran capaces de construir imágenes de la variable independiente, y en algunas ocasiones eran capaces de construir imágenes de la razón de cambio para los intervalos contiguos del dominio de una función”. Escribe la relación que él establece con el trabajo en clase, así: "El objetivo que se logró fue buscar e identificar en una función la variable independiente y la dependiente, para dar valores y poder ubicarla en una gráfica”. El informe del estudiante contiene otros párrafos del artículo seleccionado, en los cuales para su análisis procede de la misma manera como se expuso en los párrafos anteriores.

\section{Ejemplo del informe de los monitores}

La presentación del informe final de los monitores es de libre organización; algunos prefieren enviar cuadros de clasificación, mientras que otros organizan un resumen y jerarquizan aspectos a observar, como en el siguiente informe, que fue elaborado por el grupo B del primer semestre de Bacteriología y Laboratorio Clínico del 2007.

\section{Consulta revista EMA de: progresiones aritméticas o covariación \\ Grupo 1.}

Seis integrantes.

Biblioteca visitada: Universidad de los Andes.

Revista EMA del año 1998.

Informe 1. Entregado y completo.

Informe 2. Entregado y completo.

Informe 3. Entregado; éste no trae palabras claves, pero aseguran que en las revistas de este año no hay publicaciones con las palabras clave dadas. Como prueba adjuntan los artículos y el índice. Hacen referencia a los artículos y volúmenes específicos de la revista de este año, no encuentran ningún artículo sobre progresiones aritméticas o coovariación

Nota: consulté por Internet y para corroborar la información me dirigía la biblioteca Luís Ángel Arango, comprobando así que este grupo si entrego realmente los artículos de la revista y el año correspondiente. Además certifico que no hay artículos sobre coovariación o progresiones aritméticas.

\section{Grupo 3}

Cinco integrantes.

Revista EMA año 2000.

Biblioteca visitada: Luís Ángel Arango.

Informe 1. Recibido y completo.

Informe 2. No lo recibí.

Informe 3. Recibido y completo este cumple con los requisitos: índice, resumen etc. Argumentan no encontrar ningún articulo sobre coovariación o progresiones aritméticas, en este informe especifican cada volumen con el articulo y su nombre junto con las palabras claves y el índice.

Nota: al visitar la Biblioteca Luís Ángel Arango pude verificar cada uno de los volúmenes y los artículos que estos contenían, corroborando así la información entregada por este grupo. Yo hacia parte de este grupo.

\section{Seguimiento del docente y resultados}

En el primer semestre de 2007 participaron 148 estudiantes que se organizaron en 20 grupos de seis estudiantes, 4 grupos de cinco y 2 grupos de cuatro. 
Paso 1. Ocho grupos presentaron el informe escrito con las exigencias estipuladas; el resto de grupos recibieron retroalimentación en la puesta en común, tanto por parte de los demás estudiantes como indicación precisa por parte del profesor. Se observó que los estudiantes no tenían reporte escrito ni verbal alrededor de los siguientes aspectos: índice de la revista, qué clase de artículos se publican, qué temas publican, cuántos volúmenes existen de esa publicación.

En esta primera visita, los estudiantes básicamente no hicieron una revisión de las publicaciones, el $80 \%$ se limitó a ir a la biblioteca y hacer allí una revisión en la página Web de alguna revista, sin sistematizar la búsqueda. Sin embargo, todos los estudiantes manifestaron su satisfacción al conocer bibliotecas de la Universidades Pontificia Javeriana, Universidad Nacional de Colombia y la Biblioteca Pública Virgilio Barco, entre otras. De acuerdo con las observaciones al trabajo realizado, los grupos repitieron la visita y complementaron los informes escritos.

Paso 2. El total de los grupos entregaron el informe; sin embargo, 10 de ellos no identificaron por escrito cuáles eran las bases de datos a las que podían acceder. El mayor logro consistió en que todos los estudiantes tuvieron la oportunidad de comentar acerca de qué es una base de datos.

Paso 3. La consulta por palabras clave, arrojó excelentes resultados permitiendo a cada grupo informar sobre la existencia o no de artículos con esas palabras, en la revista asignada.

Paso 4. Cinco grupos establecieron frases completas enunciando vínculos entre elementos, características o dificultades establecidas en el artículo sobre el aprendizaje del concepto de covariación, y dificultades o características de su propio aprendizaje. Los otros grupos tomaron textualmente frases y dijeron algo sobre ellas, o elaboraron únicamente un resumen.

\section{Química aplicada II}

Este proceso se ha enfocado más a que sea un tema de interés general, sobre aspectos vigentes, y luego se pasa a elegir y delimitar una parte de esa gran temática que les parezca atractiva. Estas condiciones posibilitan una gama amplia de aspectos a consultar por los estudiantes de segundo semestre; en ningún momento se pretendía que se limitara al área de la química; más bien debería ser un tema de actualidad, en donde en forma abierta el estudiante se inscribiera voluntariamente, se organizara en grupos y participara en este proceso (23).

Es así como dentro de este contexto, se abordaron diferentes propuestas que van desde el estudio de una posible vida en Marte (24), hasta aspectos más generales como son las alergias $(25,26)$, la obesidad, la contaminación, medicina alternativa, protocolo Kyoto. Luego se pasa a particularizar el aspecto a tratar dentro la temática elegida, siendo importante la citación de bibliografía. De lo anterior se deduce que la temática se debe restringir y dirigir, dado que son estudiantes de primer y segundo semestres, con conocimientos académicos insuficientes para abordar artículos científicos de investigación de punta. El nombre asignado a este espacio académico inicialmente se conoció durante cinco semestres como Investigación Formativa y, en los últimos 3 semestres, se le ha denominado Orientación y Seguimiento.

\section{Pasos en la búsqueda bibliográfica}

Una vez conformados los grupos de trabajo y establecido el horario para entrega de informes verbales y asignación de tareas, se desarrollaron los siguientes pasos:

1. Búsqueda general de información. A partir del uso de palabras clave donde se incluían revistas, textos, páginas de Internet, con lo que se pretendía conocer sobre aspectos generales del tema seleccionado y, a su vez, comenzar a seleccionar las publicaciones que de alguna manera se corroboraban y daban información con un cierto grado de confiabilidad. Para ello se hizo uso de archivos verticales, catálogos de bibliotecas, bases de datos locales, revistas electrónicas, entre otros. Además, se enfatizó en la recopilación y ordenamiento de la información adquirida durante todo el semestre, para fijar las directrices a seguir.

2. Búsqueda especializada. Con base en la información general recopilada y las expectativas desarrolladas en cada grupo de trabajo, se seleccionó una temática particular para continuar con el proceso investigativo. Para lo anterior se buscaron textos que podían ser comunicaciones derivadas de simposios, o congresos, así como también en revistas científicas, siguiendo las pautas de calidad dadas por Colciencias, pero 
teniendo en cuenta en todo momento, que a los estudiantes se les facilitará el manejo de los mismos. En algunos casos, se utilizaron las entrevistas con especialistas sobre el tema.

3. Artículo de revisión. El profesor explicó las pautas para la elaboración de un artículo de revisión, teniendo presente los delineamientos establecidos por Colciencias. Mediante el correo electrónico, se les hizo llegar una copia de estos requisitos con los cuales cada grupo elabora su artículo, con base en la información recolectada durante el semestre. Finalmente, los estudiantes entregaron al docente una copia en papel y otra en medio magnético del artículo en mención, así como copias de toda la información utilizada.

4. Tanto en los pasos (1) como en el (2), se elaboró un sistema de control, que le permitía al docente verificar la asistencia de los integrantes de cada grupo, la evolución del trabajo y sugerir nuevas búsquedas.

\section{Ejemplo}

Al comienzo del período académico 1- 2006, el docente invitó a los estudiantes de segundo semestre que cursaban Química Aplicada II a participar en una actividad de investigación formativa, indicándoles el horario disponible para ello. Los estudiantes interesados en esta actividad, debían formar grupos de trabajo, máximo de 4 personas, e inscribirse en el horario de su conveniencia.

Cada grupo de estudiantes debía asistir semanalmente a entregar un reporte verbal de los avances sobre lo consultado y el docente guiaba el trabajo a seguir, teniendo en cuenta los intereses del grupo. En estas sesiones se revisaba la calidad de las fuentes, se orientaba acerca de la creación de un archivo que iría a formar parte de la bibliografía, la cual sería base para la entrega del trabajo escrito al final de este período. A la vez, el docente gestionaba esta información en un formato que él mismo había elaborado. Al finalizar el semestre, el docente envió por correo electrónico las instrucciones para la elaboración de un artículo de revisión.

En el período académico 1-2006, se inició la actividad con una consulta sobre la definición general de obesidad (27) y otros conceptos básicos como el Índice de masa corporal, anorexia y bulimia, tipos de dietas, todos ellos necesarios para una mejor comprensión y aprovechamiento de la información que debían conseguir posteriormente.

Inicialmente los estudiantes hicieron consultas en textos de nutrición, genética y endocrinología. Luego procedieron a hacer búsquedas utilizando diferentes sitios de Internet, en donde se observó la tendencia a controlar el sobrepeso por diverso mecanismos como eran las dietas (de la luna, de las proteínas, dieta Atkins, entre otros), así como el uso de diversos medicamentos (Zenical) y en casos extremos, recurrir a las cirugías. Posteriormente indagaron en revistas científicas e hicieron, en algunos casos, entrevistas a especialistas según su interés particular para profundizar y tener otro tipo de acercamiento a la información, como es el caso del uso de bypass gástrico, analizando las ventajes y desventajas de las diferentes alternativas para controlar el sobrepeso.

Cabe anotar que algunos grupos se concentraron en el estudio de enfermedades de su interés, dado que aparecían en su entorno familiar, como son la Diabetes (28) o el Síndrome de Cushing (29) Entre los títulos de los trabajos entregados se encuentran: Malos hábitos: Principio de obesidad; Tratamiento multidisciplinario para la obesidad; Las principales causas de la obesidad ocasionadas en algunas etapas de la existencia humana: gestación, niñez y menopausia; La obesidad como estado pre-diabético; Tratamiento para combatir la obesidad; Síndrome de Cushing originado a partir de la obesidad; La obesidad, una gran amenaza para la humanidad; Obesidad en niños: ¡Alerta!, una enfermedad mortal; Obesidad y sistema endocrino; La influencia de la adiponectina en la arteriosclerosis; La obesidad: fármacos más utilizados por su eficacia; Factores que intervienen en la obesidad infantil; Medicamento y enfermedades considerados factores importantes de la etiología de la obesidad (30).

\section{Seguimiento del docente y resultados}

En los 72 estudiantes del Programa de Bacteriología y Laboratorio Clínico, quienes presentaron 20 trabajos escritos, en la modalidad de artículos de revisión, se observó, en la mayoría de ellos, un notable desarrollo de la capacidad de búsqueda de información. Lo anterior se debió quizás a que se despertó curiosidad por los temas escogidos, y en algunos casos, se notó un interés particular motivado por casos clínicos muy cercanos a sus grupos familiares. 
Es de anotar que no todos los estudiantes que iniciaron el proceso lograron culminarlo, debido a que algunos no podían asistir a las horas de asesoría; otros desistieron del proceso por no contar con el tiempo necesario para ello y los demás tuvieron problemas de entendimiento entre los integrantes del grupo, lo cual ocasionó que se presentaran algunos trabajos elaborados por un solo estudiante. Estos aspectos deben tenerse en cuenta para una próxima oportunidad.

Una de las dificultades se relacionó con la incapacidad de manejar la información altamente especializada, debido a que estos estudiantes cursaban segundo semestre de carrera en el presente período, lo cual impidió que abordaran artículos relacionados con estudios genéticos o con problemas inmunológicos; sin embargo, en algunos grupos se observó la autoformación en temas específicos. Otra dificultad que se presentó, es la relacionada con publicaciones en inglés; ello ocasionaba en algunos casos apatía, ya que no todos tienen un buen manejo de este idioma. Parte de la información inicial la obtuvieron de asignaturas que cursaban en este período, en el área de la salud, lo mismo que por consulta directa con docentes de dicha área.

\section{Resultados y discusión}

Los resultados obtenidos permiten anotar las siguientes conclusiones y sugerencias: los estudiantes participantes en este proceso se familiarizaron con diferentes fuentes de información, tales como textos, publicaciones generales, artículos científicos, o consulta directa, haciendo uso de los servicios que brinda la Biblioteca Institucional, de otras universidades y de la red capital de Bibliotecas Públicas, así como la orientación de los docentes. Las actividades planeadas lograron el desarrollo de competencias para el rastreo, clasificación, análisis e interpretación de la información. Este estilo de trabajo permite a los estudiantes establecer el conocimiento como algo dinámico y progresivo. Las dos experiencias expuestas facilitan el desarrollo de habilidades en los estudiantes y los motivan para que participen en semilleros de investigación y puedan más adelante plantear su proyecto de grado. Los artículos de revisión son del campo de los expertos, sin embargo, en esta experiencia de formación, el ejercicio permite abarcar las habilidades de búsqueda, redacción y normas de citación.
Con respecto a las sugerencias, el apoyo que brindaba la Universidad en la realización de este tipo de trabajos, para la formación en investigación de los estudiantes, debe tener un espacio institucional que fortalezca la vinculación con la asignación de tiempo a los docentes de Ciencias Básicas. No sólo los semilleros de investigación y las asignaturas de metodología de la investigación, brindan las herramientas para la formación en este campo, sino que se debe rescatar el espacio de los Programas de Ciencias Básicas para desarrollar en los estudiantes estrategias conducentes a la formación de habilidades propias del quehacer investigativo.

\section{Referencias}

1. Restrepo B. Conceptos y aplicaciones de la investigación formativa, y criterios para evaluar la investigación científica en sentido estricto. http://www.cna.gov.co/cont/documentos/doc_aca/con_apl_inv_ for_cri_par_eva_inv_cie_sen_est_ber_res_gom.pdf.

2. NA. La Evaluación Externa en el Contexto de la Acreditación en Colombia. Santafé de Bogotá: Corcas. 1998

3. Eco H. Cómo se hace una tesis. http://www.inau.gub.uy/biblioteca/ Eco_Umberto__Como_se_hace_una_tesis.pdf

4. Dawson C, Martín G. El Proyecto Fin de Carrera en Ingeniería Informática: Una guía para el estudiante. Prentice Hall Pearson Educación. 2002.

5. Ramos M. Como escribir un artículo de revisión. En: Revista de Postgrado de la VIa Cátedra de Medicina. 2003;126:1-3.

6. COLCIENCIAS. Orientaciones generales de la actualización de Índice de publicaciones seriadas, científicas y tecnológicas colombianas. Publindex- 2002.

7. Magnus H. El Diablo de los Números. Editorial Siruela. 1997. p. 264.

8. Vargas J, Caycedo L. Investigación Formativa: algunas alternativas de acción con los estudiantes de Bacteriología y Laboratorio Clínico. NOVA. 2006;4:100-105.

9. Caicedo L, Vargas J. Una propuesta con estudiantes de Bacteriología: ¿Cómo abordar el proceso de medir magnitudes experimentalmente? NOVA. 2003;1:104-110.

10. Campbell N. Medición. En: El Mundo de las Matemáticas. Newman, J. V.5. Ed. Grijalbo. 1994. p. 186-201.

11. Swafford J, Langrall C. Uso Preinstruccional de Ecuaciones para describir y representar situaciones Problema en un Grupo de Sexto Grado. En: Revista EMA. 2000;5:203-235.

12. Torres L, Calderón L. El dominio de la variable: variable didáctica en el álgebra escolar. Revista EMA. 2000;5:252-266.

13. Andrade C. Dificultades en el Aprendizaje de la Noción de Variación. Revista EMA. 1998;3:241-253.

14 Hernández, E. Galindo O, Santana K. Una experiencia de diseño curricular en torno a la variación conjunta. En: Revista EMA. 2003;8:237-255. 
15. Carlson M, Jacobs S, Coe E, Larsen S, Hsu E. Razonamiento covariacional aplicado a la modelación de eventos dinámicos: Un marco conceptual y un estudio. Revista EMA. 2003;8:121-156.

16. Bravo G, Tavera C, Tibocha G. Propuesta para explorar la Comprensión de Aspectos de la Función Lineal. Revista EMA. 1999;4:166-170.

17. Hines E. Developing the concept of linear function: one student's experiences with dynamic physical models. J Mathematic Behavior. 2002;20:337-361.

18. Echeverri L. El número e. HIPÓTESIS. Apuntes Científicos Uniandinos. 2005;6:46-57.

19. Albis VS. El número e está entre 2 y 3. NOTAS 1973; p. 62-65.

20. Fernández I, Pacheco J. ¿¿Por qué son naturales los logaritmos neperianos? Epsilon. 2000;46-47:107-116.

21. De Faria E. Ingeniería Didáctica. Cuadernos de Investigación y Formación en Educación Matemática. 2006;1:1-9.

22. Puerta, F. El tratamiento gráfico de la función logarítmica. En: NÚMEROS. Revista de didáctica de las matemáticas. 1997;31:47-56.

23 Gacharná $\mathrm{H}$, Informe de orientación y seguimiento. Universidad Colegio Mayor de Cundinamarca. I- 2007, Documento de trabajo (Sin publicar).
24. Stern D, Peredo M. Nacimiento de un cinturón de radiación. htpp://www-istp.gsfc.nasa.gov/Education/Mbirthrb.html.

25. De la Fuente R, González M, Román D, Santamaría A, Armentía A, Jáuregui O. Estudio de la influencia del consumo de lácteos fermentados en una población de pacientes alérgicos. An Med Interna (Madrid). 2005;22: 55-58.

26. Pérez AJ, Fernández B, Santaolalla M, De Paz S, Domínguez AR. Síndrome de anafilaxia inducida por ejercicio. An Med Interna (Madrid). 2001;18:269-273.

27. González G y Stern M. La obesidad como factor de riesgo cardiovascular en México. Rev Invest Clin 1993;45:13-21.

28. Weyer C, Bogardus C, Mott DM, Pratley RE. The natural history of insulin secretory dysfunction and insulin resistance in the pathogenesis of type 2 diabetes mellitus. J Clin Invest. 1999; 104:787-794.

29. Arnaldi G, Angeli A, Atkinson AB, Bertagna X, Cavagnini F, Chrousos GP, Fava GA y col. Diagnosis and complications of Cushing's syndrome: a consensus statement. J Clin Endocrinol Metab. 2003;88:5593-5602.

30. Gacharná H. Informe de orientación y seguimiento. Universidad Colegio Mayor de Cundinamarca. I- 2006. Documento de trabajo (Sin publicar). 